\section{TRAUMA \\ HEALING \\ MENGGUNAKAN METODE PLAY \\ DENGAN \\ TERAPY PADA ANAK-ANAK TERKENA \\ DAMPAK TSUNAMI DI KECAMATAN SUMUR PROPINSI BANTEN}

\author{
Rahmi Mulyasih $^{1}$, Liza Diniarizki $^{2}$ \\ Prodi Komunikasi FISIPKUM Universitas Serang \\ Raya
}

*Corresponding author

Email : bikiya16@gamail.com

\begin{abstract}
Abstraksi
Tujuan dari kegiatan pengabdian masyarakat ini adalah untuk memberikan hiburan dan dukungan secara psikis sehingga dapat meminimalisasi dampak traumatis yang dihadapi pasca bencana. Metode yang digunakan dalam trauma healing pada anak-anak korban dampak tsunami di Kecamatan Sumur dengan menggunakan metode "Play Terapy". Kesimpulan penelitian ini adalah kegiatan trauma healing merupakan kegiatan yang penting untuk dilakukan bagi anak-anak korban bencana di Kecamatan. Untuk itu diperlukan adanya kerjasama dari berbagai pihak untuk secara bahu membahu membenahi infrastruktur yang rusak akibat terjangan tsunami terutama penanganan trauma yang dialami oleh anak-anak korban bencana tsunami di Kecamatan Sumur, karena bagaimana pun perjalanan hidup anak-anak di Kecamatan Sumur masih relatif panjang, anak-anak ini harus dapat bangkit dari musibah yang dialaminya dan dapat melanjutkan kehidupan ke depan sampai anak-anak ini dapat membangun wilayah tempat tinggal mereka yang luluh lantak akibat tsunami dan membanggakan orang-orang terkasih yang telah direnggut akibat adanya tsunami.
\end{abstract}

Kata kunci : Trauma Healing, Metode Play Terapy, Dampak Tsunami

\begin{abstract}
The purpose of this community service activity is to provide entertainment and support psychologically so as to minimize the traumatic impact faced by postdisaster. The method used in healing trauma in children affected by the tsunami in Sumur sub-district using the "Play Terapy" method. The conclusion of this study is that healing trauma activities are important activities to be carried out for children affected by disasters in the District. For this reason, cooperation from various parties is needed to work together to fix the infrastructure damaged by the tsunami, especially in dealing with the trauma experienced by the tsunami-affected children in Sumur Subdistrict, because after all the children's life journey in Sumur Subdistrict is still relatively long, these children must be able to rise from the calamities they have experienced and be able to continue their lives in the future until these children can build their living areas that have been devastated by the tsunami and boast loved ones who have been taken away by the tsunami.
\end{abstract}

Keywords: Trauma Healing, Therapeutic Play Method, Tsunami Impact 


\section{PENDAHULUAN}

\#Banten berduka, hastag yang memuat berita mengenai pemberitaan tsunami yang menimpa Propinsi Banten dan Lampung akibat adanya erupsi dari anak gunung krakatau hingga mengakibatkan gelombang setinggi 57 (lima puluh tujuh) meter mampu meluluh lantakan sedikitnya 5 (lima) Kabupaten yang ada di Propinsi Banten dan Lampung yaitu Pandeglang, Serang, Lampung Selatan, Pesawaran dan Tanggamus dengan menewaskan 437 orang dan menghancurkan kurang lebih 2.752 rumah warga. Propinsi Banten sendiri, wilayah yang paling parah terkena dampak tsunami adalah Kabupaten Pandeglang tepatnya di wilayah Kecamatan Sumur.

Dampak tsunami yang dapat terlihat di Kecamatan Sumur, misalnya bangunan yang rata akibat terjangan gelombang yang maha dasyat, hancurnya perahu-perahu nelayan yang merupakan mata pencaharian sebagian besar masyarakat sumur belum lagi banyaknya masyarakat yang tewas akibat tsunami yang terjadi. sehingga jika kita melihat kondisi masyarakat Sumur sangat memprihatinkan karena masyarakat yang mengungsi banyak yang mengalami kesulitan akibat bencana tsunami seperti kekurangan bahan makan, pakaian dan tempat tinggal belum lagi kesedihan akibat ditinggalkan anggota keluarga. Oleh karena itu tidak mengherankan jika bencana tsunami yang dialami oleh masyarakat di Kecamatan Sumur berdampak sangat besar bagi masyarakat di wilayah tersebut terutama bagi anak-anak.

Anak-anak yang terbiasa dengan kehidupan normal, dimana mereka terbiasa bersekolah, bermain dan berteduh di tempat tinggal mereka masing-masing. Dihadapkan pada kondisi harus tinggal di tenda-tenda pengungsian dengan keterbatasan fasilitas serta kesedihan ditinggalkan orang-orang terkasih. Untuk itu diperlukan adanya penanganan trauma bagi anak-anak korban bencana tsunami di Kecamatan Sumur, yang bertujuan untuk membantu menghilangkan rasa trauma yang mendalam pasca bencana yang dikenal dengan "trauma healing".

Terminologi "trauma" mengacu pada pengalaman yang menyebabkan reaksi stres fisik dan psikologis yang intens. "Trauma dihasilkan dari suatu peristiwa, serangkaian peristiwa, atau serangkaian keadaan yang dialami oleh seseorang sebagai berbahaya atau mengancam secara fisik atau emosional dan yang memiliki efek buruk yang bertahan lama pada fungsi individu dan kesejahteraan fisik, 
sosial, emosional, atau spiritual. (SAMHSA's, 2012

Trauma healing sangat diperlukan bagi anak-anak karena pada dasarnya anak-anak belum mampu untuk mengartikulasikan perasaan yang dirasakan akibat adanya musibah tsunami, anak-anak juga cenderung masih kesulitan untuk bercerita mengenai kecemasan dan ketakutan yang dirasakan.

\section{METODE PELAKSANAAN}

Metode yang digunakan adalah Participatory Learning And Action yang merupakan proses belajar secara berkelompok yang dilakukan secara interaktif dalam suatu proses kerja (Appel dkk, 2012 dalam Sururi \& Mulyasih, 2017). Dalam kegiatan diterapkan metode Trauma Healing pada anak-anak yang terkena dampak bencana tsunami yang bertujuan untuk memberikan hiburan dan dukungan secara psikis sehingga dapat meminimalisasi dampak traumatis yang dihadapi pasca bencana. Metode yang digunakan dalam trauma healing pada anakanak korban dampak tsunami di Kecamatan Sumur dengan menggunakan metode "Play Terapy".

\section{HASIL DAN PEMBAHASAN}

Trauma healing bagi anak-anak korban tsunami sangat diperlukan, hal ini dikarena dengan adanya bencana alam berupa tsunami yang terjadi di Kecamatan Sumur, akan menimbulkan dampak trauma tersendiri bagi anak-anak sehingga diperlukan adanya penanganan khusus salah satunya dengan diadakan trauma healing. Trauma healing sendiri bertujuan untuk memberikan hiburan dan dukungan secara psikis sehingga dapat meminimalisasi dampak traumatis yang dihadapi pasca bencana. Metode yang digunakan dalam trauma healing pada anakanak korban dampak tsunami di Kecamatan Sumur dengan menggunakan metode "Play Terapy".

Play Terapy menjadi pilihan dalam metode penanganan trauma healing bagi anakanak yang terkena dampak, karena bermain merupakan media yang alami sehingga dapat digunakan dalam mengungkapkan diri sehingga anak-anak akan kembali kedunia anak-anak yang ceria dan bahagia. Dalam play terapy, anak-anak melakukan berbagai permainan yang dapat menghibur, melakukan aktivitas-aktivitas yang dapat mendorong anak menjadi lebih kreatif seperti menggambar, bernyanyi dan sebagainya.

Play terapy yang dilakukan pada anakanak di Kecamatan Sumur diawali dengan meneriakan "Kita Semua Bergembira”, hal ini ditujukan agar anak-anak dapat melepaskan rasa trauma akibat tsunami sehingga rasa gelisah, ketakutan dan rasa cemas dapat 
dilepaskan dengan berteriak sekencangkencangnya. Jika diamati trauma yang dialami oleh anak-anak di Kecamatan Sumur masih sangat terlihat seperti masih tersisa rasa takut ketika terdengar bunyi yang relatif sangat keras, sedih, cenderung menghindar ketika didekati, dan kurang responsif terhadap beragam emosi. Padahal perjalanan hidup dari anak-anak di Kecamatan Sumur ini masih sangat panjang, oleh karenanya diperlukan adanya peran aktif dari berbagai elemen masyarakat untuk bersama-sama melakukan berbagai perbaikan pada wilayah-wilayah yang terkena dampak tsunami, terutama perbaikan jiwa pada anak-anak yang trauma karena adanya tsunami.

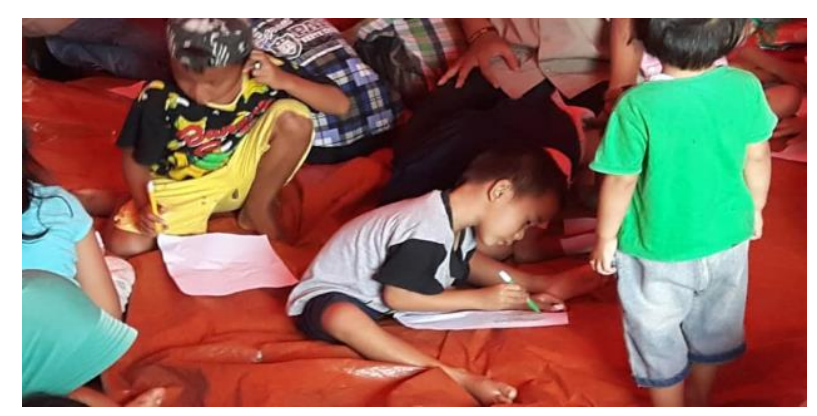

Setelah melepaskan beban dan rasa sesak yang menghimpit di diri anak-anak pasca tsunami, kemudian anak-anak dibagi kedalam kelompok yang sesuai dengan usianya untuk melakukan aktivitas menggambar. Di sini anak-anak boleh menyalurkan imajinasinya dengan menggambar apa saja sesuai dengan keinginan mereka. Tujuan dari diadakannya menggambar agar anak-anak dapat menyalurkan imajinasinya untuk menganalisa pengalaman yang menyakitkan, dengan menyalurkan imajinasi dalam bentuk gambar sehingga diharapkan anak-anak secara perlahan dapat merubah hidupnya sehingga tidak hanya berjibaku dengan rasa sedih akibat kehilangan orang-orang terkasih atau rasa takut akibat tsunami yang masih ada didalam benak mereka

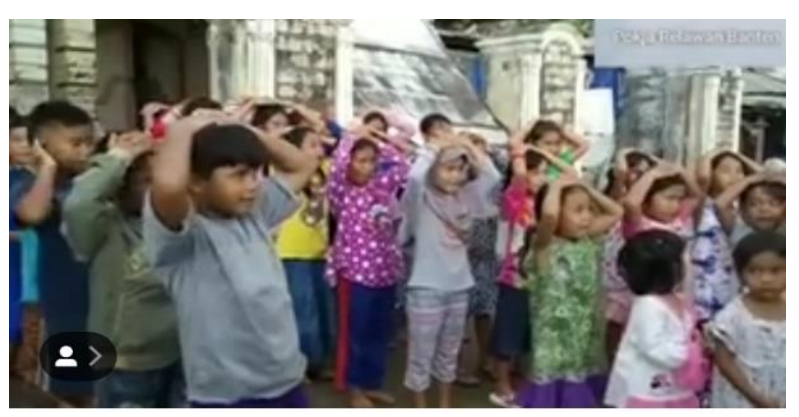

Kegiatan berikutnya dalam play terapi adalah, mengajak anak-anak untuk menari. Dengan melakukan gerakan menari anak-anak mendapatkan pengalaman dalam mengekspresikan pikiran dan perasaan positif. Menari bersifat rekreatif, sehingga dapat membantu anak-anak mengekpresikan emosi dirinya sehingga dapat menyeimbangkan tubuh dan jiwanya. Karena pada dasarnya, tidak semua anak dapat mengungkapkan perasaan pasca bencana secara verbal, sehingga dengan dilakukanya gerakan menari anak-anak dapat mengungkapkan permasalahan dan perasaanya secara non verbal.

Setelah menari anak-anak diajak melakukan game yang dinamakan dengan board game, game ini bertujuan untuk 
memberikan pengetahuan tentang cara menghindari dari bencana dengan menggunakan papan permainan, dadu, pion karakter, pion bencana, kartu bencana, dan kartu siaga. Permaianan ini kemudian diberi nama "Siaga" yang kepanjangan dari siapkan anak berlindung menghadapi bencana. Permainan ini terdiri dari dua sampai empat orang pemain dengan waktu permaianan 1 (satu) sampai dengan 1,5 (satu setengah) jam, permainan ini dilakukan pada sebuah papan yang dibagi kedalam 4 layer kemudian papan dibagi ke dalam 4 jenis warna yaitu merah, biru, kuning dan hijau. Pada setiap bagian dibagi kedalam 5 bagian. Setiap pemain dapat memilih satu sampai empat karakater yang tersedia dan meletakkan di tempat mulai atau di angka 1 yang merupakan layer terluar.

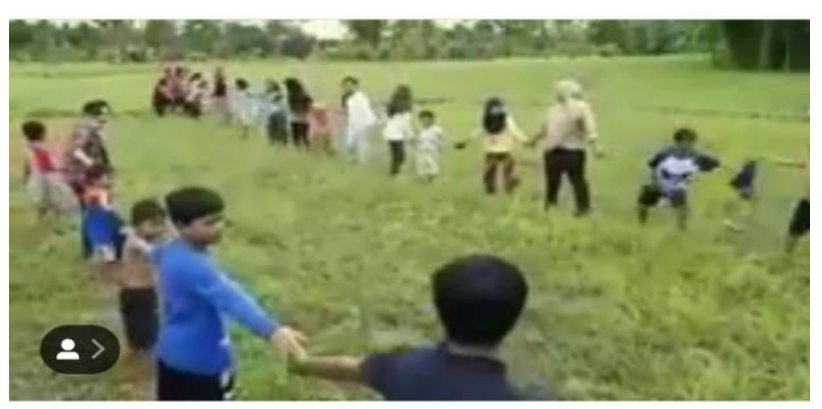

Kemudian pemain mengocok dadu untuk menempati posisi bencana, setelah semua pemain telah menempati posisi maka pemain pertama mengocok dadu kembali untuk memulai permainan, permainanan akan berakhir ketika para pemain telah mencapai garis finish dengan ditandai adanya gambar
"Siaga". Untuk mkncapai garis finish, para pemain harus melalui semua layer warna secara keseluruhan. Pemain ketika menggerakan pion karakter maka pemain juga harus mengocok dadu untuk menggerakkan pion bencana yang berguna untuk mengalahkan pemain lain sebab jika pion bencana berhenti di suatu kotak yang sama dengan pion karakter maka karakter tersebut akan mati.Setiap pemain juga mendapatkan satu set kartu yang acak berisi kartu bencana dan kartu siaga, kartu-kartu ini berguna untuk menyerang dan menyelamatkan diri dari bencana yang dihadapi maupun untuk mempercepat jalannya permainan.

Dengan adanya permainan ini, anakanak di Kecamatan Sumur terlihat sangat menikmati karena permainan ini di desain agar anak-anak tidak merasa takut akan bencana yang dialami, selain itu terdapat pengetahuan dari kartu bencana bagaimana cara menangani bencana yang terjadi.

Permainan board game telah selesai kemudian anak-anak bergandengan tangan satu sama lain dengan cara memanjang, hal ini dilakukan untuk membentuk rasa empati dan kerjasama bahwa anak-anak tidak sendirian dalam menghadapi bencana tsunami tetapi banyak saudara, teman dan masyarakat yang akan siap membantu permasalahan yang dihadapi anak-anak di Kecamatan Sumur baik 
dalam segi sarana prasarana fisik maupun mental. Karena bagaimana pun teragedi tsunami yang meluluh lantakan perkampungan mereka, pasti akan membuat kesedihan yang mendalam bagi anak-anak dan ketakutan yang akan membuat trauma tersendiri bagi anakanak, untuk itu diperlukan adanya saling kerjasama dari berbagai pihak contoh aplikasi dari kerjasama dan penguatan mental serta memotivasi naka-anak untuk tetap kuat dan tegar salah satunya dengan saling berpegangan tangan satu sama lain.

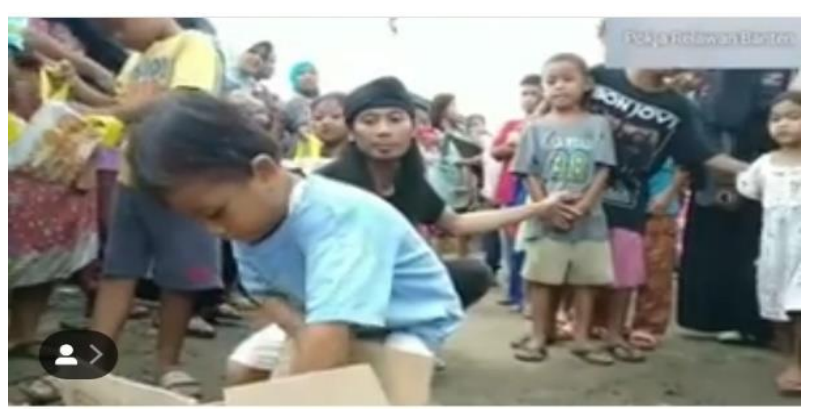

Kegiatan trauma healing satu persatu telah dilaksanakan setiap tahapannya, kegiatan terakhir adalah pembagian makanan dan minuman berupa susu untuk anak-anak sebagai bentuk hadiah karena anak-anak telah berpartisipasi secara aktif dan memberikan sedikit kebahagian, selain itu makanan ringan dan susu pun dapat menambah asupan nutrisi yang sangat diperlukan bagi anak-anak.

\section{Evaluasi Hasil Penilaian Kegiatan}

Kegiatan trauma healing, merupakan kegiatan yang penting untuk dilakukan bagi anak-anak korban bencana di Kecamatan Sumur. Karena dengan adanya trauma healing dengan berbagai kegiatan yang dilakukan mulai dari menggambar, menari, melakukan games siaga sampai saling mendukung dengan berpegangan tangan membuat anak-anak dapat tertawa dan mencurahkan perasaanya dengan berbagai kegiatan yang ada di taruama healing.

Pada awalnya, anak-anak yang saat ini menetap di tenda-tenda pengungsian merasakan kebosanan karena tidak adanya kegiatan lain yang dapat mereka lakukan. Selain itu ketakutan akibat tsunami masih terlihat dari raut muka anak-anak di Kecamatan Sumur, sampai ada sebagian anak-anak yang masih merasa kurang nyaman jika didatangi orang asing. Tetapi ketika kegiatan trauma healing mulai dilakukan anak-anak malah terlihat antusias melakukan berbagai kegiatan bahkan mereka bisa tertawa dengan lepas.

Pada sesi menggambar, ada salah satu anak bernama Husni yang menggambar bukit yang dibawahnya jalan raya disebelahnya pantai. Husni langsung menyatakan bahwa ia “tidak takut pantai". Perasaan yang dapat ia luapkan dengan apa yang ada di gambar merupakan luapan perasaan yang tidak bisa ia ungkapkan secara verbal kepada orang lain. Ketika Husni berkata bahwa ia tidak takut pada pantai, bisa jadi sebetulnya ia takut pada pantai yang telah mengambil ibu yang dikasihinya. 
Dan yang menarik dari kegiatan menari, anak-anak dengan tertawa mengikuti gerakan menari yang dicontohkan oleh para relawan. Anak-anak tertawa karena merasa bahwa gerakan yang dicontohkan oleh kakak-kakak relawan sangat lucu, belum lagi melihat temantemannya melakukan gerakan. Anak-anak yang tadinya masih memperlihatkan muka sedih dan murung dapat tertawa lepas di kegiatan menari.

Siaga merupakan games yang dirasakan paling menyenangkan bagi anak-anak, karena dengan siaga anak-anak dapat memperoleh pengetahuan dalam menghadapi bencana secara tidak membosankan, karena games siaga dilakukan seperti permainan monopoli anakanak menjadi antusias dan menertawakan temanya ketika temanya harus mengakhiri permainan karena pion bencana masuk ke dalam kotak yang sama dengan pion karakter sehingga permainan harus berakhir.

Berpegangan tangan satu sama lain, merupakan kegiatan terakhir dari trauma healing yang dilakukan di Kecamatan Sumur. Di sini, anak-anak merasakan adanya kekuatan kasih sayang, rasa empati dan kekuatan untuk menghadapi permasalahan yang dihadapi pasca adanya bencana tsunami yang menimpa wilayah mereka. Dari rasa itu, maka ketika permainan berpegangan tangan berakhir mereka masih saling berpelukan untuk menguatkan perasaan mereka.

\section{PENUTUP}

Musibah berupa bencana alam yang dialami masyarakat di Kecamatan Sumur memang tidak dapat dihindari, namun bagi anak-anak musibah yang merenggut sebagian anggota keluarga dan menghilangkan harta benda pasti akan menyisakan kesedihan. Untuk itu diperlukan adanya kerjasama dari berbagai pihak untuk secara bahu membahu membenahi infrastruktur yang rusak akibat terjangan tsunami terutama penanganan trauma yang dialami oleh anak-anak korban bencana tsunami di Kecamatan Sumur, karena bagaimana pun perjalanan hidup anak-anak di Kecamatan Sumur masih relatif panjang, anakanak ini harus dapat bangkit dari musibah yang dialaminya dan dapat melanjutkan kehidupan ke depan sampai anak-anak ini dapat membangun wilayah tempat tinggal mereka yang luluh lantak akibat tsunami dan membanggakan orang-orang terkasih yang telah direnggut akibat adanya tsunami.

\section{REFERENSI}

Sururi, A., \& Mulyasih, R. (2017). Pemberdayaan Masyarakat melalui Inovasi Perencanaan Pembangunan berbasis 4R (Rembug, Rencana, Realisasi dan Rawat) di Desa Cilangkap Kecamatan Wanasalam sebagai Pilar Utama Kebijakan Partisipatif dan Gotong Royong. Engagament Jurnal Pengabdian Masyarakat, 1(2). 
Rahmi Mulyasih \& Liza Dinarizki P, Bantenese Jurnal Pengabdian Masyarakat, Volume 1 Nomor 1 Tahun 2019.

Substance Abuse and Mental Health Services Administration, Trauma and Justice Strategic Initiative. SAMHSA's working definition of trauma and guidance for trauma-informed approach. Rockville, MD: Substance Abuse and Mental Health Services Administration; 2012.

Theresia, Aprillia, at al, 2014, Pembangunan Berbasis Masyarakat. Bandung, Alfabeta 